\title{
Correction to: Employing gene chip technology for monitoring and assessing soil heavy metal pollution
}

\author{
ZiChun Lu $\cdot$ HaiFeng Su
}

Published online: 28 February 2022

(C) Springer Nature Switzerland AG 2022

\section{Correction to: Environ Monit Assess (2022) 194:2 https://doi.org/10.1007/s10661-021-09650-6}

The original version of this article unfortunately contained an error in the affiliation section.

The affiliation of the first author, was incorrectly captured. The correct author affiliation is shown below and in affiliation section.

School of River and Ocean Engineering, Chongqing Jiaotong University, Chongqing 400074, PR China.

Publisher's Note Springer Nature remains neutral with regard to jurisdictional claims in published maps and institutional affiliations.

The original article can be found online at https://doi.org/ 10.1007/s10661-021-09650-6.

Z. Lu

School of River and Ocean Engineering, Chongqing

Jiaotong University, Chongqing 400074, PR China

Z. Lu $\cdot$ H. Su

Chongqing Institute of Green and Intelligent Technology,

Chinese Academy of Science, Chongqing 400714, China

H. Su $(\bowtie)$

Key Laboratory of Degraded and Unused Land Consolidation Engineering, the Ministry of Natural and Resources, Xi' an, Shanxi 710075, China e-mail: suhaifeng@cigit.ac.cn 